\section{Performance as a function of payment, commitment, and task interest}

RICHARD HESLIN and BRIAN BLAKE, Purdue University, West Lafayette, Ind. 47907

The present study analyzes dissonance and incentive responses to being under-or overpaid for performance. $A U$-shaped curve of performance as a function of amount of payment was hypothesized. It was also hypothesized that Ss who commit themselves to the importance of a task perform better than those who do not, and that they are more affected by both underpayment and overpayment conditions than uncommitted Ss. For the first and third hypotheses, trends were in the expected direction; the second hypothesis received clear support.

Cognitive dissonance is aroused when a person has insufficient justification for engaging in a negative (boring, immoral, embarrassing, etc.) activity (Brehm \& Cohen, 1962). In the present study which concerns underpayment and overpayment, we would expect the underpayment condition to be the dissonance condition, i.e., people who are underpaid should experience dissonance because they have insufficient justification for working on the activity. One means of reducing dissonance is to find challenge in the task and thereby fill the absence of extrinsic justification with intrinsic justification. To meet the task challenge, the $S$ should work hard on the task; he should try to do well on it (Weick, 1966).

In the greater-than-usual payment (overpayment) condition, a dissonance response would not be expected since the $S$ hasmore than adequate justification for working on the task. As indicated by Aronson (1966), Ss in such a condition should show an incentive response. That is, given an absence of cognitive dissonance due to insufficient justification, the $S$ should attempt to bring his level of work up to his level of pay.

Finally, in the usual payment condition, the $\mathrm{S}$ should experience no disson ance, since he has sufficient justification for working on the task. Therefore, as in the overpayment condition, we should find an incentive effect working. However, since the payment given was the typical amount, little actual incentive should have been felt. Thus, greater effort should be expended in the high dissonance and high incentive conditions than in the typical payment condition, yielding a U-shaped curve of performance as a function of payment.
The study also deals with the effect of a participant committing himself (before he begins) to the position that the study is of scientific importance.

"This hypothesis [that much of the motivation of the $S$ to comply with any and all experimental instructions derives from an identification with the goals of science in general and the success of the experiment in particular] is subject to empirical test. We should predict that there would be measurable differences in motivation between Ss who perceive a particular experiment as 'significant' and those who perceive the experiment as 'unimportant' [Orne, 1962, p. 788] ."

Those who commit themselves to the scientific importance of a study should differ from those who do not in two ways. First, they should work harder on the task, and second, the effects found using all Ss should appear in greater strength among the committed $S s$, and they should appear in less strength among those who did not feel that the study was important. The expectation was that to the extent a person feels that an activity in which he is engaged is important, he cannot, by definition, behave as if it were trivial or inconsequential.

A third variable of interest was the possible effect upon the relation between payment and performance of the kind of task used. It was expected that a more interesting task would be less susceptible to a dissonance response in an underpayment condition since the interestingness of the working on it despite the low payment. Such a reduction in dissonance should cause a positive linear relation between payment and effort while for the boring task the hypothesized U-shaped function should obtain. Packing spools in a box repeatedly was taken as the low-interest task and a jigsaw puzzle as the high-interest task.

Three hypotheses were made; all assume that the middle of the payment distribution represents typical payment. These hypotheses were: (1) There is a U-shaped relation between payment and performance on a boring task and a linear relation between payment and performance on an interesting task;(2) those committed to the importance of a task situation perform better than those who are not so committed; and (3) those committed to the importance of a task situation are more responsive to payment inequities than those who are not so committed. task would provide partial justification for

\section{METHOD}

Seventy-two undergraduates were obtained by the posting of sign-up sheets and by telephone. 1 The design in which they were run consisted of the following factors: (1) high vs low commitment, (2) interesting vs boring task, and (3) underpayment vs typical vs overpayment. All factors were between-S analv ses.

Each $S$ was informed of the usual payment for participation in a study of this sort (one credit or $\$ 1.25$ ) and told how much he would receive for participation (underpayment-\$.25 or one credit for two sessions; usual payment; overpayment- $\$ 3.00$ or credit plus $\$ 1.25$ ).

After completing the payment transaction, the E explained the task and showed the materials to the S. Half of the Ss were told that they were to pack spools in a box over and over; the other half were told that they were to try to comple te a jigsaw puzzle.

Having viewed the task materials, Ss were asked to rate the task situation before beginning the task on how important a contribution to science would be made by this task. Ss were divided into high and low commitment groups on the basis of their contribution to science rating. The $E$ then told the $S$ to begin the task and left the room. When the allotted $13 \mathrm{~min}$ had passed, he returned, noted the $S$ 's performance, and asked him to rate his interest in the task on a 7-point graphic scale.

RESULTS AND DISCUSSION

The jigsaw puzzle was rated significantly $(F=10.06, \mathrm{df}=1,70, \mathrm{p}<.01)$ higher on interest than the spool-packing task, thus verifying the task interest manipulation.

It was also necessary to test whether or not the computationally simple procedures using orthogonal polynomials could be used to test for trends, i.e., whether the three levels of payment approximated equal distances. Twelve pilot Ss (using three graphic scales each divided into nine areas) rated: (a) the amounts, $\$ .25, \$ 1.25$, and $\$ 3.00$; (b) the same amounts given that the typical amount should be $\$ 1.25$; and (c) their feelings if they received one of these amounts and were told by an $E$, "...the usual payment for... [the statements made to each experimental condition were given]." When the pilot group rated the money paid to the $S$ s, mean difference between $\$ .25$ and $\$ 1.25$ was 1.7 and the difference between $\$ 1.25$ and $\$ 3.00$ was 2.7 . When they rated the amount, given that the typical payment was $\$ 1.25$, the respective differences were 3.5 and 3.5 . When they rated the feelings they would have had if they received that amount of money with the given explanation, the respective differences were 3.1 and 3.1 . Thus, as was expected when the amounts were selected, the psychological difference 
between typical pay (\$1.25) and overpay $(\$ 3.00)$ is the same as the psychological distance between typical pay $(\$ 1.25)$ and underpay (\$.25).

The effects of payment level on performance are depicted in Fig. 1. As hypothesized, the U-shaped curve was obtained for the Ss who worked on the boring task, but not for those who worked on the interesting task, supporting the view that the interesting task provided justification in the underpayment condition. However, even though the trends were in the hypothesized direction, they did not reach significance.

The main effect of level of commitment on performance was tested for performance in packing spools and in completing the jigsaw puzzle. Since the dependent variable of units completed was different for each task, the hypothesis was tested separately for the two tasks and the significance levels were combined (Winer, 1962, p. 43). As can be seen in Fig. 2, those who had committed themselves that the experiment was scientifically important outperformed those who had committed themselves to the position that it was not $(\mathrm{p}<.01)$.

Finally, it was hypothesized that those who commit themselves that an experiment is scientifically important show both dissonance and incentive effects more strongly, thereby generating a clearer U-shaped curve of performance as a function of payment than those who view the experimental situation as less important.

Figure 2 depicts the relationship. Although the trends were in the hypothesized direction, they did not reach significance.

The role of committing oneself to a task situation is just beginning to be appreciated for its effect on behavior. In earlier research a group that committed itself to lie to a judge was compared to a group that only role-played a debate. The liars were much more responsive to social reinforcement from the judge than the "debaters" (Heslin \& Rotton, 1969). Thus Aronson's (1966) position that uninvolving artificial situations will not yield a dissonance effect and therefore will show an incentive effect needs to be extended. If the situation is uninvolving or viewed as unimportant, the $S$ will tend to show neither a dissonance nor an incentive effect. In fact, involvement can be viewed as a generalized arouser and sensitizer that makes a $S$ work harder and be more responsive to reinforcement cues in the situation

In summary, three hypotheses were made: (1) There is a U-shaped function between payment and performance on a boring task, and a linear relation on an interesting task; (2) Ss committed to the importance of a situation perform better
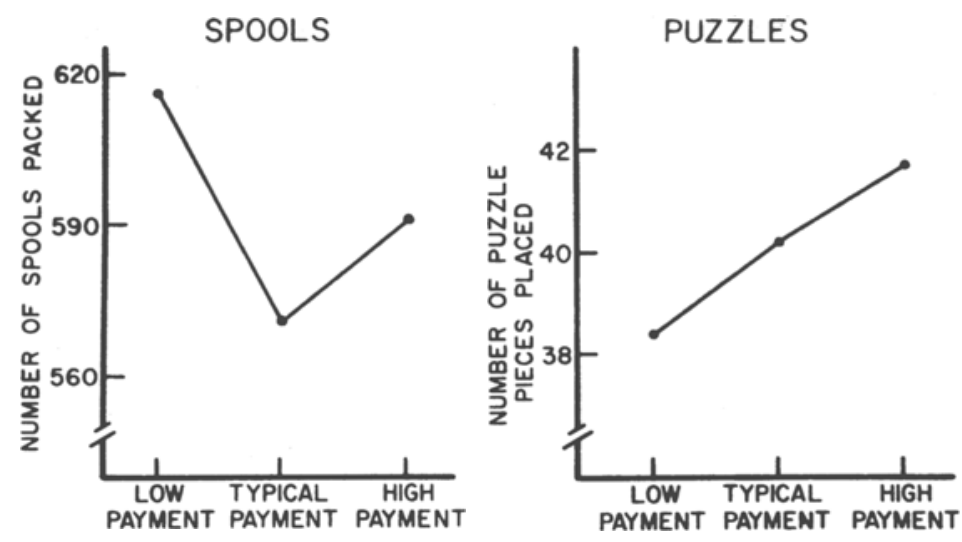

Fig. 1. Performance as a function of payment level.
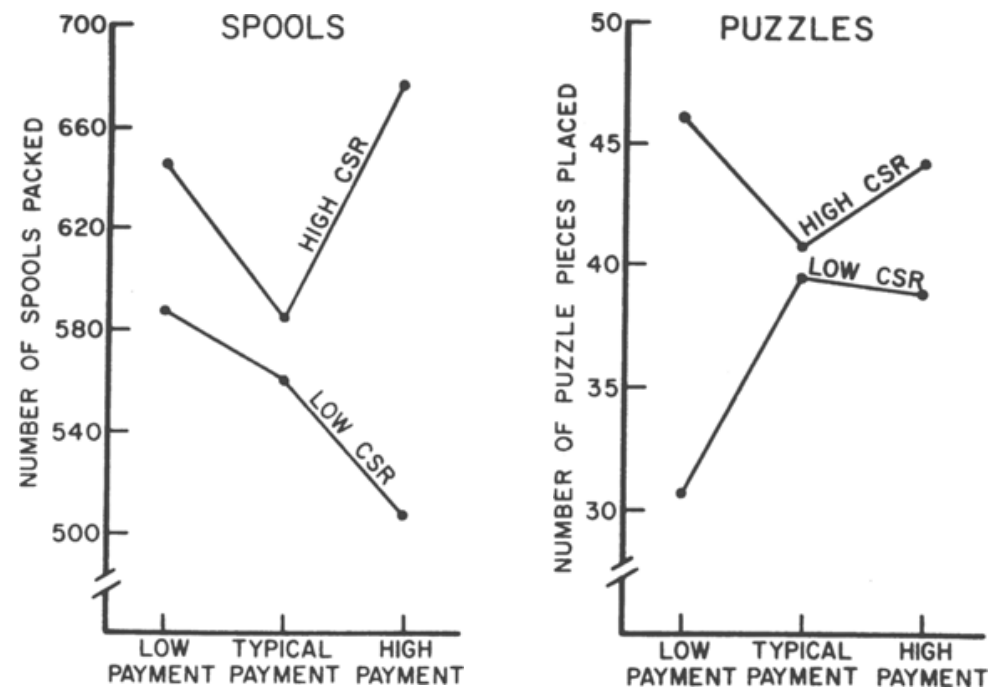

Fig. 2. Performance as a function of payment level and commitment to science response.

than those who do not so commit themselves; and (3) committed Ss manifest hypothesized relations better than uncommitted Ss. For Hypotheses 1 and 3, trends were in the expected ( $U$-shaped and linear) directions. Hypothesis 2 was clearly ( $p<.01$ ) supported.

\section{REFERENCES}

ARONSON, E. The psychology of insufficient justification: An analysis of some conflicting data. In S. Feldman (Ed.), Cognitive consistency. New York: Academic Press, 1966. Pp. 115-136.

BREHM, J. W., \& COHEN, A. R. Explorations in cognitive dissonance. New York: Wiley, 1962.

CARLSMITH, J. M., COLLINS, B., \& HELMREICH, R. Studies in forced compliance: 1. The effect of pressure for compliance on attitude change produced by face-to-face role playing and anony mous essay writing. Journal of Personality \& Social Psychology, 1966, 4, 1-13.

HESLIN, R., \& ROTTON, J. Incentive or dissonance effects of reinforcement for counterattitudinal advocacy. Proceedings 77 th Annual Convention, APA, 1969, 311-312.
ORNE, M. T. On the social psychology of the psychological experiment: With particular reference to demand characteristics and their implications. American Psychologist, 1962, 17, 776-783.

SCOTT, W. Attitude change through reward of verbal behavior. Journal of Abnormal \& Social Psy chology, 1957, 55, 72-75.

SCOTT, $W$. Attitude change by response reinforcement: Replication and extension. Sociometry, 1959, 22, 328-335.

WEICK, K. E. Task acceptance dilemmas: A site for research on cognition. In S. Feldman (Ed.), Cognitive consistency. New York: Academic Press, 1966. Pp. 225-255.

WINER, B. J. Statistical principles in experimental design. New York: McGraw-Hill, 1962.

NOTE

1. It was thought that there might be differences between Ss who were paid with money and those who were paid with experimental credit. Since this variable made no difference in any comparison, it was dropped from the analysis. 